\title{
A ReView of EXISTING MASONRY ARCH BRIDGES in CroAtia
}

\author{
Domagoj Trajber, Davorin Penava, Fulvio Rinaudo, \\ Vasilis Sarhosis \& Lars Abrahamczyk
}
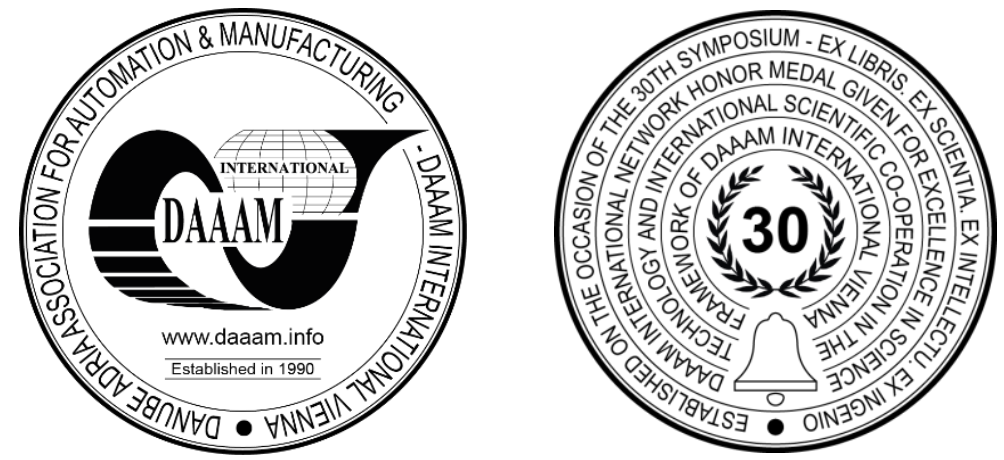

This Publication has to be referred as: Trajber, D[omagoj]; Penava, D[avorin]; Rinaudo, F[ulvio]; Sarhosis, V[asilis] \& Abrahamczyk, L[ars] (2021). A Review of Existing Masonry Arch Bridges in Croatia, Proceedings of the 32nd DAAAM International Symposium, pp.0740-0744, B. Katalinic (Ed.), Published by DAAAM International, ISBN 9783-902734-33-4, ISSN 1726-9679, Vienna, Austria

DOI: $10.2507 / 32$ nd.daaam.proceedings.103

\begin{abstract}
This study offers a review of masonry arch bridges in Croatia, it presents their most common typologies, geometric characteristics, and damages. Data about bridges have been collected from official institutions, state archives, and conservation institutes. Statistical analysis considering materials, arch geometry, arch thickness, number of spans, and superstructure type was conducted using collected data. The most common typologies are stone bridges with constant arch thickness, closed spandrel walls, and circular arch for the single-span and segmental arch for multi-span bridges. Additional data about geometry and damage of road brickwork bridges has been obtained with a rapid visual in-situ inspection. Observed damages indicate the need for further investigation for purpose of better understanding the capacity of these bridges, to secure their safe use through adequate maintenance and retrofitting.
\end{abstract}

Keywords: masonry arch bridges; construction material; typology; geometry; damage.

\section{Introduction}

There are approximately 300000 masonry arch bridges on railway and national road systems networks across Europe [1]. Papers e.g. [2], [3], [4] are just some of the papers published that offer a review of masonry arch bridges in some European countries. The majority of these bridges are over 100 years old. During their lifetime they have been exposed to natural hazards, extreme weather conditions, and ever-increasing traffic loads. These effects cause material degradation, deformation, and damage development which decreases the load-bearing capacity of bridges and brings their safety to question. This highlights the need for a reliable assessment method of masonry bridges. [5] gives a review of experimental investigations and assessment methods for masonry bridges. Currently, there is no unified database of masonry arch bridges in Croatia, nor are they classified in any manner. This hinders research that looks to assess their serviceability state and load-bearing capabilities. This work presents data collected on masonry arch bridges and results of statistical processing.

Statistical processing of data on masonry arch bridges in Croatia, obtained from authorized institutions: Croatian Railways, Croatian Roads and the County Road Administration, State Archives and Restoration Institutes, determined that there are approximately 178 masonry arch bridges. The majority of them are located on roadways (85\%), while the rest are on railways $(15 \%)$. 
They were mostly built during the second half of the 19th and the first half of the 20th century out of locally available materials, clay bricks in continental regions and natural stone in mountain and coastal regions. Two of the oldest bridges (Figure 1.) that are still in use today were built at the beginning of the $18^{\text {th }}$ century.

Data were collected and processed for railway and road bridges made out of both stone and clay bricks. However, further research will be limited only to brickwork road bridges. For that reason, more detailed data about geometry and damage of brickwork bridges was obtained by fast visual in-situ inspection. The need for a more detailed inspection to assess the condition of these bridges was identified based on observed damage, to continue their intended use and preserve durability with appropriate maintenance and repair measures.
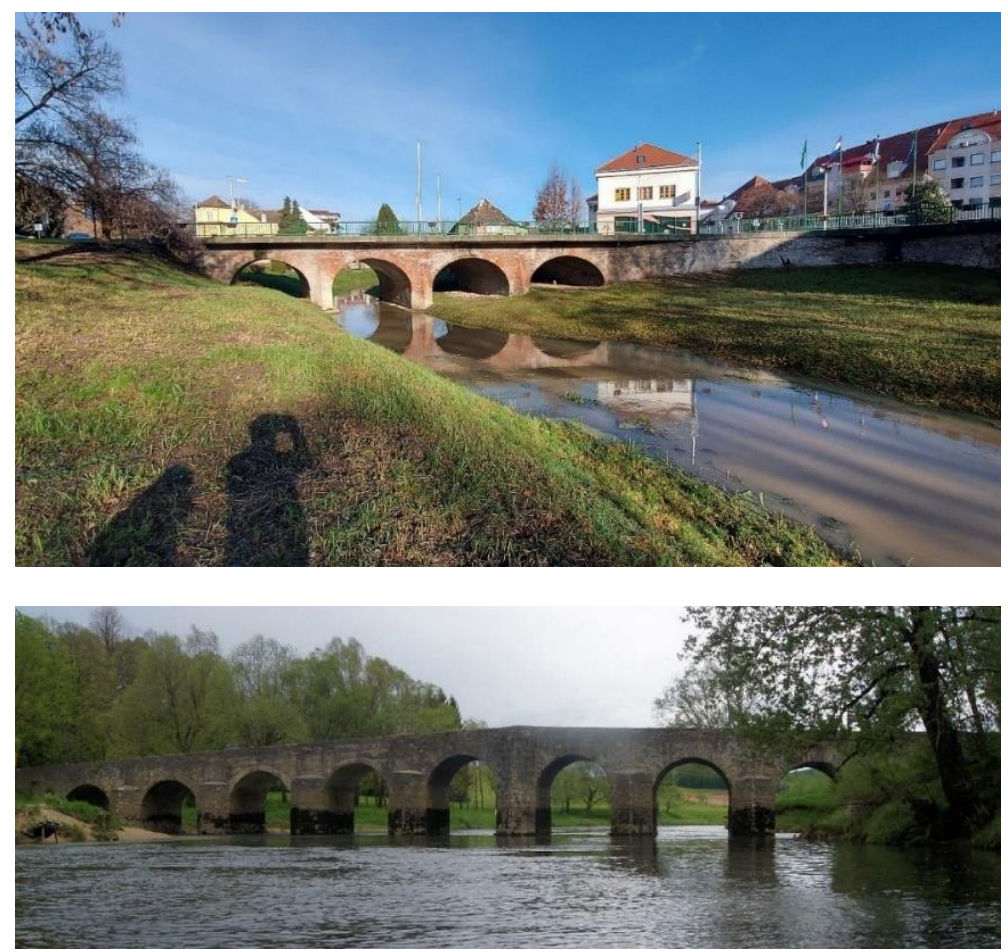

Fig. 1. Old bridge Valpovo (top) (image source: author) Bridge on river Dobra (bottom) (image source: Google)

\section{Typological characteristics}

Based on typological characteristics, masonry arch bridges have been classified in accordance with [4], with an adjustment that included segmental arches and excluded irregular arches (as they were not registered). Characteristics considered were: materials, arch geometry, arch thickness, number of spans and superstructure type (Table 1.).

\begin{tabular}{|c|c|c|}
\hline \multirow{3}{*}{ Material } & \multirow{3}{*}{$\rightarrow$} & Brick \\
\hline & & Stone \\
\hline & & Combination of both \\
\hline \multirow{5}{*}{ Arch geometry } & \multirow{5}{*}{$\rightarrow$} & Half-circle \\
\hline & & Parabolic \\
\hline & & Elliptical \\
\hline & & Segmental \\
\hline & & Inclined \\
\hline \multirow{2}{*}{ Arch thickness } & \multirow{2}{*}{$\rightarrow$} & Constant \\
\hline & & Variable \\
\hline \multirow{2}{*}{ Number of spans } & \multirow{2}{*}{$\rightarrow$} & Single-span \\
\hline & & Multi-span \\
\hline \multirow{2}{*}{ Spandrel walls } & \multirow{2}{*}{$\rightarrow$} & Closed \\
\hline & & Open \\
\hline
\end{tabular}

Table 1. Classification of masonry arch bridges according to typological characteristics 
Statistical analysis of collected data gives the following results:

- $86 \%$ of bridges are made out of natural stone, $13 \%$ out of brick, and the remaining $1 \%$ is a combination of both materials

- most represented types of arch geometry are segmental and circular arches, presenting $28 \%$ and $25 \%$ of bridge stock respectively.

- $69 \%$ of bridges have a constant arch thickness

- around $66 \%$ of bridges are single-span, while the rest (33\%) are multi-span bridges

- the most common typologies are stone bridges with constant arch thickness, and closed spandrel walls, with circular arch for single-span (15\%) and segmental arch for multi-span bridges (10\%)

\section{Geometrical characteristics}

To compare masonry arch bridges according to their geometrical characteristics, data about the number of spans, span length, rise, arch geometry, and thickness of arch in crown and springing was. Bridges were then classified into six groups in accordance with [6], three of which are based on rise to span length ratio, and the remaining three on span length.

Groups based on rise to span length ratio are:

- shallow arches

$0.00<\mathrm{r} / \mathrm{s} \leq 0.25$,

- semi-shallow arches

- deep arches

$0.25<\mathrm{r} / \mathrm{s} \leq 0.40$,

$0.40<\mathrm{r} / \mathrm{s}$.

Groups based on span length are:

- short span

- medium span

- large span

$0.0<\mathrm{s} \leq 7.5$

$7.5<\mathrm{s} \leq 15.0$,

$15.0<\mathrm{s}$.

Figure 2 shows the relationship between the rise to span length ratio and span length, as well as corresponding areas of bridge groups. The frequency of bridges certain groups is shown in Table 2 .

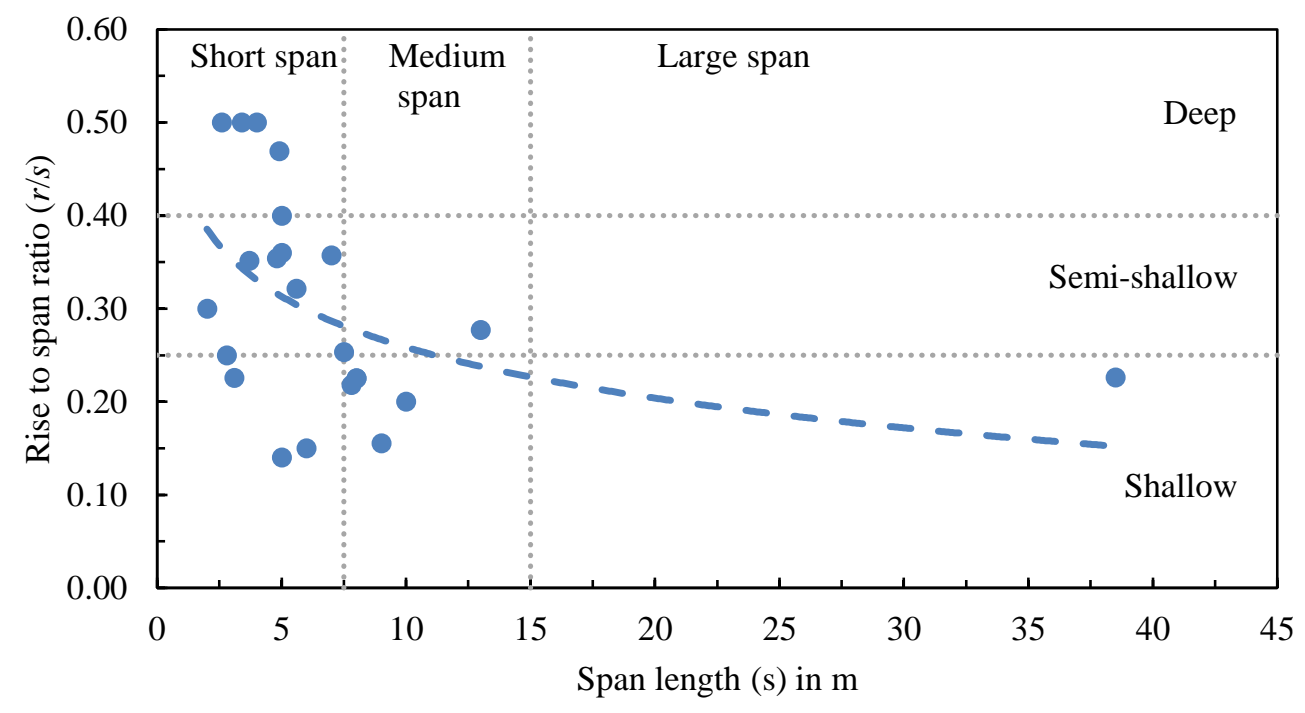

$r / s$ to $s$ relationship $\quad \ldots . .$. border $\quad-\quad$ trendline

Fig. 2. Relation between rise to span length ratio (r/s) and span length (s)

\begin{tabular}{|c|c|c|c|c|}
\hline & Short span & Medium span & Large span & $\Sigma$ \\
\hline Deep arch & $\mathbf{4 ( 1 8 \% )}$ & - & - & $4(18 \%)$ \\
\hline Semi-shallow arch & $\mathbf{7 ( 3 0 \% )}$ & $\mathbf{1 ( 4 \% )}$ & - & $8(34 \%)$ \\
\hline Shallow arch & $\mathbf{4 ( 1 8 \% )}$ & $\mathbf{6 ( 2 6 \% )}$ & $\mathbf{1 ( 4 \% )}$ & $11(48 \%)$ \\
\hline$\Sigma$ & $15(66 \%)$ & $7(30 \%)$ & $1(4 \%)$ & \\
\hline
\end{tabular}

Table 2. Classification of masonry arch bridges according to relation between rise to span length ratio (r/s) and span length (s) 
Based on geometrical features, three reference brickwork spans of road bridges have been selected. Large-span bridges and bridges with deep arches were not considered here because of their low frequency. Geometrical characteristics of reference brickwork spans are shown in Table 3.

\begin{tabular}{|c|c|c|}
\hline \multirow{4}{*}{ Short span } & Semi-shallow arch & Shallow arch \\
\hline & $\mathrm{s}=4,70 \mathrm{~m}$ & $\mathrm{~s}=4,20 \mathrm{~m}$ \\
\cline { 2 - 3 } & $\mathrm{r} / \mathrm{s}=0,35$ & $\mathrm{r} / \mathrm{s}=0,20$ \\
\cline { 2 - 3 } & $\mathrm{d}_{\mathrm{c}}=0,60 \mathrm{~m}$ & $\mathrm{~d}_{\mathrm{c}}=0,60 \mathrm{~m}$ \\
\cline { 2 - 3 } & $($ Bridge $\mathrm{A})$ & $($ Bridge $\mathrm{B})$ \\
\hline \multirow{4}{*}{ Medium span } & \multirow{3}{*}{-} & $\mathrm{s}=8,40 \mathrm{~m}$ \\
\cline { 2 - 3 } & & $\mathrm{r} / \mathrm{s}=0,20$ \\
\cline { 2 - 3 } & & $\mathrm{d}_{\mathrm{c}}=0,80 \mathrm{~m}$ \\
\cline { 2 - 3 } & & $($ Bridge $\mathrm{C})$ \\
\hline
\end{tabular}

Table 3. Geometrical characteristics of reference brickwork spans

\section{Damage and in-situ inspection of bridges}

During their life span arch bridges are exposed to damages which affect their load-bearing capacities, and serviceability. Damages are mostly caused by deterioration of material due to environmental effects, age and inadequate maintenance. In accordance with [7] damages are classified into six categories:

- contamination - appearance of any type of plant vegetation or dirtiness

- deformation - geometry changes (deflection of backfill, protection or masonry, and slipping and swelling of masonry)

- destruction - the deterioration of physical and chemical structural features (such effects can be recognized for example by spalling and/or chipping of bricks)

- discontinuity - cracks

- displacement - displacement of the whole structure or its structural components (rotation or translation of spandrel walls)

- loss of material

In-situ visual inspection and classification of damages has been conducted for 22 brickwork road arch bridges (Fig. 3). Most commonly occurring damages are contamination, destruction and loss of material. Salt attack and moss growth are the most common types of contamination, and in some cases water penetration and heavy vegetation were noticed. There were also a few cases of significant discontinuities, like ring separation, and possible detachment of spandrel walls from arch. These kinds of damages cause significant loss of load-bearing capacity and should be repaired as soon as possible.

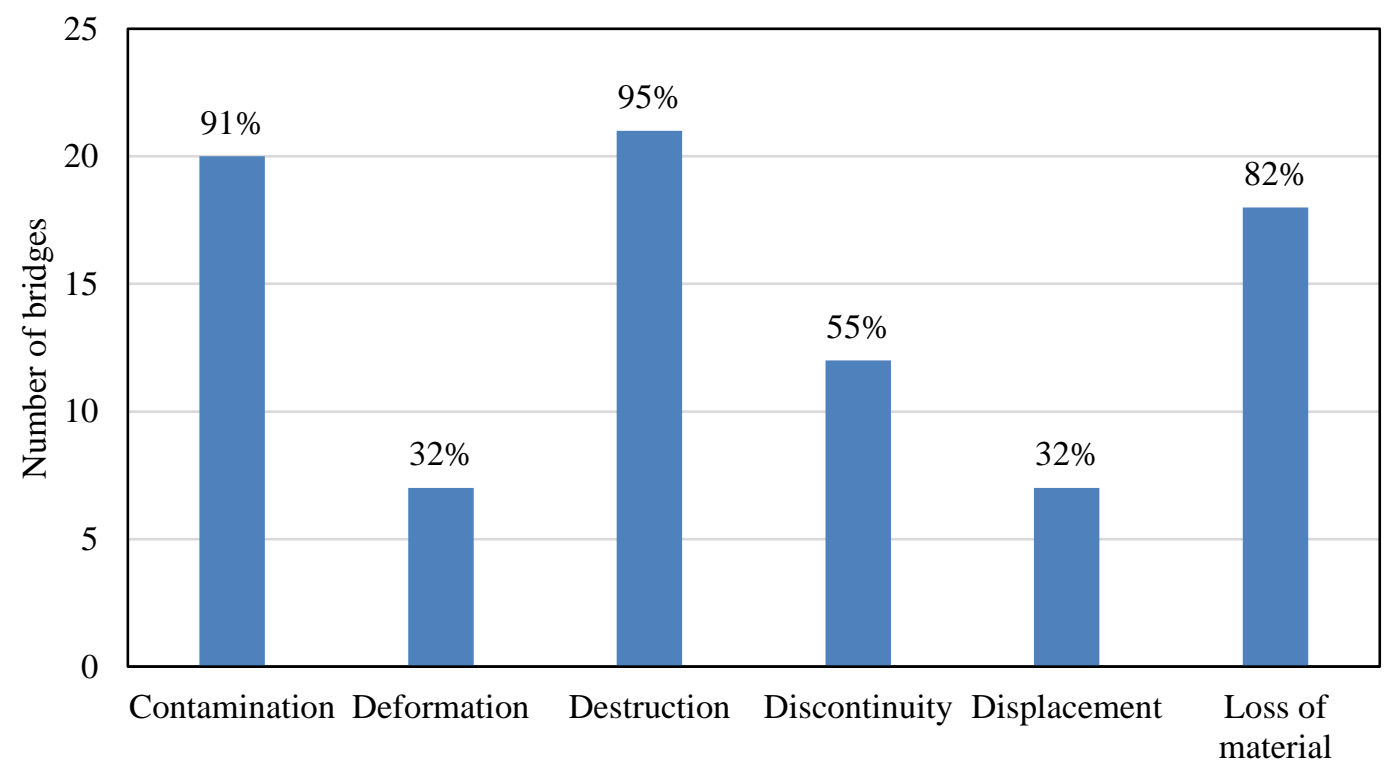

Type of damage

Fig. 3. Relation between rise to span length ratio (r/s) and span length (s) 


\section{Conclusion}

Currently, there is no unified database of masonry arch bridges in Croatia, nor are they classified in any manner. This hinders research that looks to assess the serviceability state and load-bearing capabilities of those bridges. Data about bridges have been collected from official institutions, state archives, and conservation institutes, as well as by visual insitu inspection. Classification of bridges by their typological features was conducted, based on which most common typologies were found. Since further work will be focused on brickwork roadway bridges additional classification of them by their geometrical features gave three reference brickwork spans. Reference brickwork span will be used to develop experimental and computer models, to provide a reliable assessment of serviceability state and load-bearing capacity of bridges. Damages observed during visual in-situ inspection imply the need for further detailed inspection to assess the state of bridges, to secure their safe use through adequate maintenance and retrofitting. The number of masonry arch bridges in Croatia is modest when compared to other European countries. However, they are an essential part of transportation infrastructure and construction heritage.

\section{Acknowledgments}

This research has been conducted with the support of the Erasmus+ programme of the European Union project "Environmental Risk Assessment and Mitigation on Cultural Heritage Assets in Central Asia - ERAMCA" (Project Reference: 609574-EPP-1-2019-1-IT-EPPKA2-CBHE-JP) and Croatian Science Foundation (HRZZ) "Young Researchers' Career Development Project - Training of Doctoral Students" programme. The authors are also grateful to Croatian Railways, Croatian Roads, County Road Administrations, and Croatian State Archives for providing the data that contributed to this research.

\section{References}

[1] Brencich, A.; Morbiducci, R. (2007). "Masonry Arches: Historical Rules and Modern Mechanics", International journal architectural heritage, Vol. 1, No. 2, 2007, pp. 165-189., DOI: 10.1080/15583050701312926.

[2] De Santis, S.; De Felice, G. (2014). "Overview of railway masonry bridges with a safety factor estimate", International journal architectural heritage, Vol. 8, No. 3, 2014, pp. 452-474., DOI: 10.1080/15583058.2013.826298.

[3] Page, J. (1993). Masonry arch bridges. State of the art review, The Stationery Office, ISBN: 0115511903, United Kingdom

[4] Bień, J.; Kamiński, T. (2004). Masonry arch bridges in Poland, Proceedings of the 4th International Conference on Arch Bridges, Roca, P. \& Oñate, E. (Ed.), pp. 10, Barcelona

[5] Sarhosis, V.; De Santis, S. \& De Felice, G. (2016). “A review of experimental investigations and assessment methods for masonry arch bridges”, Structure and Infrastructure Engineering, Vol. 12, No. 11, 2016, pp. 1439-1464., ISSN: 1573 - 2479, DOI: 10.1080/15732479.2015.1136655.

[6] Olivera, D. V.; Lourenco, P. B. \& Lemos, C. (2010). “Geometric issues and ultimate load capacity of masonry arch bridges from the northwest Iberian Peninsula”, Engineering Structures, Vol. 32, No. 12, 2010, pp. 3955-3965, DOI: 10.1016/j.engstruct.2010.09.006.

[7] Bień, J.; Kamiński, T. (2007). Damages to masonry arch bridges - proposal for treminology unification, Proceedings of the 5th International Conference on Arch Bridges, ISBN: 9789728692315, Lourenço, Paulo, B. (Ed.), pp. 341348, Madeira 